\title{
Note on a discrete initial value problem from a competition
}

Stevo Stević $\mathfrak{c}^{1,2^{*}}$

${ }^{*}$ Correspondence: sstevic@ptt.rs
${ }^{1}$ Mathematical Institute of the
Serbian Academy of Sciences, Knez
Mihailova 36/III, 11000, Beograd,
Serbia
${ }^{2}$ Department of Medical Research,
China Medical University Hospital,
China Medical University, Taichung,
40402, Taiwan, Republic of China

\begin{abstract}
The following discrete initial value problem

$$
x_{n+1}=x_{n}\left(x_{n-1}^{2}-2\right)-x_{1}, \quad n \in \mathbb{N},
$$

$x_{0}=2$ and $x_{1}=5 / 2$, appeared at an international competition. It is known that the problem can be solved in closed form. Here we discuss the solvability of a more general initial value problem which includes the former one. We show that, in a sense, there are not so many solvable discrete initial value problems related to this one, showing its specificity, which is a bit surprising result.
\end{abstract}

MSC: Primary 39A20; secondary 39A06

Keywords: Discrete initial value problem; Nonlinear difference equation; Closed-form formula; Solvable equation

\section{Introduction}

Throughout the paper we use the standard notations $\mathbb{N}, \mathbb{N}_{0}, \mathbb{Z}, \mathbb{R}, \mathbb{R}_{+}, \mathbb{R}_{-}, \mathbb{C}$ for the sets of natural numbers, nonnegative integers, integers, real numbers, positive real numbers, negative real numbers, and complex numbers, respectively. If $m, n \in \mathbb{Z}$ are such that $m \leq n$, then the notation $j=\overline{m, n}$ is used instead of writing $m \leq j \leq n$.

Solvability of recursive relations/difference equations has been studied for a long time (see, for example, [3-11, 13-18, 20-39] and the related references therein).

The following recursive relation

$$
x_{n+1}=a_{1} x_{n}+a_{2} x_{n-1}, \quad n \in \mathbb{N},
$$

where $a_{1}, a_{2} \in \mathbb{R}$ are such that

$$
a_{2} \neq 0 \text { and } a_{1}^{2} \neq-4 a_{2} \text {, }
$$

(c) The Author(s) 2021. This article is licensed under a Creative Commons Attribution 4.0 International License, which permits use, sharing, adaptation, distribution and reproduction in any medium or format, as long as you give appropriate credit to the original author(s) and the source, provide a link to the Creative Commons licence, and indicate if changes were made. The images or other third party material in this article are included in the article's Creative Commons licence, unless indicated otherwise in a credit line to the material. If material is not included in the article's Creative Commons licence and your intended use is not permitted by statutory regulation or exceeds the permitted use, you will need to obtain permission directly from the copyright holder. To view a copy of this licence, visit http://creativecommons.org/licenses/by/4.0/. 
is one of the first which was solved in closed form. Namely, the following closed-form formula

$$
x_{n}=\frac{\left(x_{1}-\lambda_{2} x_{0}\right) \lambda_{1}^{n}+\left(\lambda_{1} x_{0}-x_{1}\right) \lambda_{2}^{n}}{\lambda_{1}-\lambda_{2}}, \quad n \in \mathbb{N}_{0},
$$

where $\lambda_{1}$ and $\lambda_{2}$ are the roots of the associated polynomial

$$
Q_{2}(\lambda)=\lambda^{2}-a_{1} \lambda-a_{2}
$$

was proved in [7] (see also [8]).

Note that the posed conditions on the coefficients $a_{1}$ and $a_{2}$ in (2) ensure that the zeros of polynomial $Q_{2}$ are different. Formula (3) was obtained for the first time by using the method of generating functions.

More closed-form formulas of this type, including those when the corresponding associated polynomials have multiple zeros, can be found in [9]. The method of looking for solutions to recursive relation (1) in the form of a geometric progression, that is,

$$
x_{n}=\lambda^{n}, \quad n \in \mathbb{N}_{0}
$$

for some $\lambda \in \mathbb{R}$, was proposed in [5], whereas the method of decomposing linear operators for getting their solutions was proposed in [14]. By using any of the above-mentioned methods, formula (3) can be obtained. As a basic one, the formula is widely used in many areas of mathematics and science. It will be also used in this note for a few times.

For some other early results on solvability of linear and nonlinear difference equations and systems of difference equations, see also [13] and [15]. Some presentations of solvability theory, their applications, as well as other topics related to the equations and systems, can be found, for example, in the books $[6,10,11,16-18,20,39]$. For some recent results in this and related topics such as finding and using invariants of difference equations and systems, see, for example, [3, 4, 21-38]. It should be noticed that solvability of linear difference equations and systems of difference equations implies solvability of many nonlinear solvable ones (see, for example, $[4,24,27-34,36-38]$ and the related references therein). The main point in these papers is that the problem of solving nonlinear difference equations and systems therein is transferred to the problem of solving some linear ones.

If a difference equation or system of difference equations has a form of a known trigonometric formula this could be a sign that a closed-form formula for its general solution exists. Of course, this principle can be also used in the cases when a difference equation or system has a form of a trigonometric formula which is not so known (there are many trigonometric formulas and it is clearly impossible to know all of them). This is an old idea for guessing solvability of a difference equation or a system (see, for example, [6]). In fact, it essentially appeared in paper [15] by Laplace. We have had recently such a situation in $[27,32,37,38]$, where the so-called hyperbolic-cotangent classes of difference equations and systems were studied, and in [35], where the solvability of a class of the so-called hyperbolic-cosine-type difference equations was studied.

\subsection{An IMO problem and its official solution}

The following problem was posed at the 18th International Mathematical Olympiad in 1976 (see, for example, [1] and [19]): 
Problem 1 Let $u_{n}, n \in \mathbb{N}_{0}$ be a sequence defined by

$$
\begin{aligned}
& u_{0}=2, \quad u_{1}=\frac{5}{2}, \\
& u_{n+1}=u_{n}\left(u_{n-1}^{2}-2\right)-u_{1}, \quad n \in \mathbb{N} .
\end{aligned}
$$

Show that

$$
\left[u_{n}\right]=2^{\frac{2^{n}-(-1)^{n}}{3}}, \quad n \in \mathbb{N}_{0},
$$

where $[x]$ denotes the greatest integer not exceeding number $x$.

In [1] and [19], it is suggested calculation of the first several members of the sequence $\left(u_{n}\right)_{n \in \mathbb{N}_{0}}$. The idea is to guess the following closed-form formula:

$$
u_{n}=2^{\frac{2^{n}-(-1)^{n}}{3}}+2^{-\frac{2^{n}-(-1)^{n}}{3}}, \quad n \in \mathbb{N}_{0}
$$

which is then proved by induction, and from which the problem is easily solved, bearing in mind that the sequence

$$
2^{\frac{2^{n}-(-1)^{n}}{3}}=2^{\sum_{j=0}^{n-1} 2^{j}(-1)^{n-j-1}}, \quad n \in \mathbb{N}_{0},
$$

consists of natural numbers, whereas each member of the sequence

$$
2^{-\frac{2^{n}-(-1)^{n}}{3}}, \quad n \in \mathbb{N},
$$

belongs to the interval $(0,1)$.

This solution, although natural for high-school students, looked a bit artificial for us. One of the reasons for this was the fact that behind existence of a closed-form formula for solutions to nonlinear difference equations and systems of difference equations usually lies a method, along with some tricks, for solving them (as we have already mentioned many nonlinear difference equations are transformed to linear solvable ones by suitable changes of variables), and in the case of initial value problem (5)-(6) we have a closedform formula for the problem. For these reasons we have tried to find a more natural and constructive/analytic method for solving the problem. We have found such a solution at the beginning of the 1980s. The solution is now also well known. In fact, we solved a slightly generalized initial value problem by using the method which we present for the completeness and as a motivation for the study in the note.

\subsection{Second solution}

Consider the following initial value problem:

$$
x_{n+1}=x_{n}\left(x_{n-1}^{2}-2\right)-x_{1},
$$

where $x_{0} \in \mathbb{R}$,

$$
\left|x_{0}\right|=2 \quad \text { and } \quad x_{1}=a+\frac{1}{a}
$$

for some $a \in \mathbb{C} \backslash\{0\}$. 
First, it is good to calculate the first several members of the sequence $\left(x_{n}\right)_{n \in \mathbb{N}_{0}}$ to see if something can be concluded about the solution form from such obtained expressions. By some simple calculations, we have

$$
\begin{aligned}
& x_{2}=x_{1}\left(x_{0}^{2}-2\right)-x_{1}=\left(a+\frac{1}{a}\right)\left(x_{0}^{2}-3\right)=a+\frac{1}{a}, \\
& x_{3}=x_{2}\left(x_{1}^{2}-2\right)-x_{1}=\left(a+\frac{1}{a}\right)\left(a^{2}+\frac{1}{a^{2}}\right)-\left(a+\frac{1}{a}\right)=a^{3}+\frac{1}{a^{3}}, \\
& x_{4}=x_{3}\left(x_{2}^{2}-2\right)-x_{1}=\left(a^{3}+\frac{1}{a^{3}}\right)\left(a^{2}+\frac{1}{a^{2}}\right)-\left(a+\frac{1}{a}\right)=a^{5}+\frac{1}{a^{5}}, \\
& x_{5}=x_{4}\left(x_{3}^{2}-2\right)-x_{1}=\left(a^{5}+\frac{1}{a^{5}}\right)\left(a^{6}+\frac{1}{a^{6}}\right)-\left(a+\frac{1}{a}\right)=a^{11}+\frac{1}{a^{11}}, \\
& x_{6}=x_{5}\left(x_{4}^{2}-2\right)-x_{1}=\left(a^{11}+\frac{1}{a^{11}}\right)\left(a^{10}+\frac{1}{a^{10}}\right)-\left(a+\frac{1}{a}\right)=a^{21}+\frac{1}{a^{21}} .
\end{aligned}
$$

Formulas (9)-(13) strikingly suggest that the solution to the initial value problem has the following form:

$$
x_{n}=a^{b_{n}}+\frac{1}{a^{b_{n}}}
$$

for $n \in \mathbb{N}_{0}$.

By using (14) in (7), we have

$$
\begin{aligned}
a^{b_{n+1}}+\frac{1}{a^{b_{n+1}}} & =\left(a^{b_{n}}+\frac{1}{a^{b_{n}}}\right)\left(a^{2 b_{n-1}}+\frac{1}{a^{2 b_{n-1}}}\right)-x_{1} \\
& =a^{b_{n}+2 b_{n-1}}+\frac{1}{a^{b_{n}+2 b_{n-1}}}+a^{b_{n}-2 b_{n-1}}+\frac{1}{a^{b_{n}-2 b_{n-1}}}-x_{1}
\end{aligned}
$$

for $n \in \mathbb{N}$.

From (9)-(13) and (15) it is natural to assume that the sequence $\left(b_{n}\right)_{n \in \mathbb{N}_{0}}$ satisfies the following relation:

$$
b_{n+1}=b_{n}+2 b_{n-1}, \quad n \in \mathbb{N} .
$$

Since, when $x_{0}=2$, we have $b_{0}=0$ and $b_{1}=1$, and the roots of the characteristic polynomial

$$
\widetilde{P}_{2}(\lambda)=\lambda^{2}-\lambda-2
$$

associated with equation (16) are $\lambda_{1}=2$ and $\lambda_{2}=-1$, by using de Moivre formula (3), we have

$$
b_{n}=\frac{2^{n}-(-1)^{n}}{3}, \quad n \in \mathbb{N}_{0} .
$$

On the other hand, from (17) we have

$$
b_{n}-2 b_{n-1}=\frac{\left(2^{n}-(-1)^{n}\right)-2\left(2^{n-1}-(-1)^{n-1}\right)}{3}=(-1)^{n-1}, \quad n \in \mathbb{N} .
$$


Relation (18) is a surprising and very useful fact since it leads to the following unexpected relation:

$$
a^{b_{n}-2 b_{n-1}}+\frac{1}{a^{b_{n}-2 b_{n-1}}}=a^{(-1)^{n-1}}+a^{(-1)^{n}}=x_{1}, \quad n \in \mathbb{N} .
$$

Now, from (15) and (19) we see that (14) is the solution to initial value problem (7)(8), where $b_{n}$ is defined in (17), that is, we have the following closed-form formula for the initial value problem:

$$
x_{n}=a^{\frac{2^{n}-(-1)^{n}}{3}}+a^{-\frac{2^{n}-(-1)^{n}}{3}}, \quad n \in \mathbb{N}_{0} \text {. }
$$

Note also that if $x_{0}=-2$, then (20) holds, but for $n \in \mathbb{N}$. So, we have proved a bit more than what is requested in the problem. Namely, we have proved that the following result holds.

Proposition 1 Let the sequence $\left(x_{n}\right)_{n \in \mathbb{N}_{0}}$ be the solution to equation (7) satisfying the initial conditions in (8), where $a \in \mathbb{C} \backslash\{0\}$. Then the sequence is given by closed-form formula (20).

\subsection{A sequence of polynomials}

Here we define a sequence of polynomials whose special cases frequently appear in the literature, although many mathematicians could not be aware of it (for example, in solving polynomial equations with symmetric coefficients $[2,12])$. Let $P_{m}(t)$, where $m \in \mathbb{N}$, be a polynomial satisfying the following relation:

$$
P_{m}\left(z+\frac{1}{z}\right)=z^{m}+\frac{1}{z^{m}}, \quad z \neq 0 .
$$

It is shown that the sequence can be also defined by the initial values

$$
\begin{aligned}
& P_{1}(t)=t, \\
& P_{2}(t)=t^{2}-2,
\end{aligned}
$$

and the recursive relation

$$
P_{m+1}(t)-t P_{m}(t)+P_{m-1}(t)=0, \quad m \geq 2,
$$

(see, e.g., [35]).

Since relation (23) is a homogeneous linear difference equation of second order, which for each fixed $t$ is with constant coefficients, we have that initial value problem (22)-(23) is a standard one. Hence, it can be also solved by using de Moivre formula (3), from which a closed-form formula for the initial value problem is obtained. The formula is not used here, because of that it is omitted. The interested reader can find the formula, for example, in [35].

\subsection{Aim of this note}

It is a natural problem to see if initial value problem (7)-(8) is a special case of another one, for which it is also possible to find a solution in closed form. This note is devoted to the problem. In the next section we give an answer to the problem, which is a bit surprising. 
Namely, we show that, in a sense, there are not so many solvable initial value problems related to (7)-(8), and that they essentially belong to a natural class containing the problem from the 18th International Mathematical Olympiad.

\section{An extension of initial value problem (7)-(8)}

In view of the second solution of Problem 1 and the fact that equation (7) can be written in the form

$$
x_{n+1}=P_{1}\left(x_{n}\right) P_{2}\left(x_{n-1}\right)-a-a^{-1}, \quad n \in \mathbb{N},
$$

it is quite natural to study solvability of initial value problems for the following extension to the equation:

$$
x_{n+1}=P_{k}\left(x_{n}\right) P_{l}\left(x_{n-1}\right)-a^{c}-a^{-c}, \quad n \in \mathbb{N},
$$

where $k, l \in \mathbb{N}, c \in \mathbb{R}, a \in \mathbb{C} \backslash\{0\}$, and polynomials $P_{k}$ and $P_{l}$ are two members of the sequence of polynomials defined by (22) and (23).

Hence, it is of some interest to find the difference equations of the form in (24) for which the corresponding initial value problems have solutions of the form given in (14).

First note that from (14) and (21) we have

$$
P_{s}\left(x_{n}\right)=a^{s b_{n}}+\frac{1}{a^{s b_{n}}}, \quad n \in \mathbb{N}_{0},
$$

for each $s \in \mathbb{N}$.

Employing (25) in (24) it follows that

$$
\begin{aligned}
& a^{b_{n+1}}+a^{-b_{n+1}} \\
& =\left(a^{k b_{n}}+a^{-k b_{n}}\right)\left(a^{l b_{n-1}}+a^{-l b_{n-1}}\right)-a^{c}-a^{-c} \\
& =a^{k b_{n}+l b_{n-1}}+a^{-\left(k b_{n}+l b_{n-1}\right)}+a^{k b_{n}-l b_{n-1}}+a^{-\left(k b_{n}-l b_{n-1}\right)}-a^{c}-a^{-c}
\end{aligned}
$$

for $n \in \mathbb{N}$.

Following the main idea from the second solution of Problem 1, we choose a sequence $\left(b_{n}\right)_{n \in \mathbb{N}_{0}}$ so that the following linear recursive relation of second order holds:

$$
b_{n+1}=k b_{n}+l b_{n-1}
$$

for every $n \in \mathbb{N}$, as well as one of the following four linear recursive relations of the first order:

$$
\begin{aligned}
& k b_{n}-l b_{n-1}=c, \\
& k b_{n}-l b_{n-1}=-c, \\
& k b_{n}-l b_{n-1}=c(-1)^{n}, \\
& k b_{n}-l b_{n-1}=c(-1)^{n-1}
\end{aligned}
$$

for $n \in \mathbb{N}$. 
Let

$$
P_{2}(\lambda)=\lambda^{2}-k \lambda-l
$$

and $p$ and $q$ be its roots, that is,

$$
p=\frac{k+\sqrt{k^{2}+4 l}}{2}
$$

and

$$
q=\frac{k-\sqrt{k^{2}+4 l}}{2} .
$$

Note that $k^{2}+4 l \geq 5>0$, since $k, l \in \mathbb{N}$, from which it follows that $p, q \in \mathbb{R}$, and that

$$
p q=-l \leq-1
$$

Moreover, $p \in \mathbb{R}_{+}$, whereas $q \in \mathbb{R}_{-}$, since $k<\sqrt{k^{2}+4 l}$ for $k, l \in \mathbb{N}$. Since

$$
p+q=k \in \mathbb{N} \text { and } p-q=\sqrt{k^{2}+4 l} \geq \sqrt{5},
$$

we also have

$$
p \geq \frac{1+\sqrt{5}}{2} \text { and } p>|q|
$$

By de Moivre formula, we have

$$
b_{n}=\frac{\left(b_{1}-q b_{0}\right) p^{n}+\left(p b_{0}-b_{1}\right) q^{n}}{p-q}, \quad n \in \mathbb{N}_{0} .
$$

Now, we want to check which of the sequences in (34) satisfy one of the relations in (28)-(31).

We have four cases to be considered.

Case 1. Relation (28) holds. Then, by using (34) in (28), we have that it must be

$$
\left(b_{1}-q b_{0}\right)(k p-l) p^{n-1}+\left(p b_{0}-b_{1}\right)(k q-l) q^{n-1}=c(p-q), \quad n \in \mathbb{N} .
$$

Relation (35) means that the sequence

$$
\alpha_{n}:=\left(b_{1}-q b_{0}\right)(k p-l) p^{n-1}+\left(p b_{0}-b_{1}\right)(k q-l) q^{n-1}, \quad n \in \mathbb{N},
$$

is constant.

Assume

$$
\left(b_{1}-q b_{0}\right)(k p-l) \neq 0 \neq\left(p b_{0}-b_{1}\right)(k q-l) .
$$


Then, by dividing both sides of relation (35) by $p^{n-1}$, we have that it must be

$$
\left(b_{1}-q b_{0}\right)(k p-l)+\left(p b_{0}-b_{1}\right)(k q-l)\left(\frac{q}{p}\right)^{n-1}=\frac{c(p-q)}{p^{n-1}}, \quad n \in \mathbb{N}
$$

By letting $n \rightarrow+\infty$ in (38) and using (33), we get

$$
\left(b_{1}-q b_{0}\right)(k p-l)=0 .
$$

However, (39) contradicts one of the assumptions in (37), from which it follows that (35) cannot hold in this case.

Now assume

$$
\left(b_{1}-q b_{0}\right)(k p-l) \neq 0=\left(p b_{0}-b_{1}\right)(k q-l) .
$$

Then we have

$$
\alpha_{n}=\left(b_{1}-q b_{0}\right)(k p-l) p^{n-1}, \quad n \in \mathbb{N} .
$$

From (32) and (40), we have

$$
\left(b_{1}-q b_{0}\right)(k p-l) p \neq 0
$$

from which it follows that $\alpha_{n} \neq 0$ for every $n \in \mathbb{N}$. On the other hand, since (33) holds, it follows that $\alpha_{n}$ cannot be a constant sequence (moreover, from (33) and (41) it follows that the sequence must be unbounded), and consequently (35) also cannot hold in this case.

Now assume

$$
\left(b_{1}-q b_{0}\right)(k p-l)=0 \neq\left(p b_{0}-b_{1}\right)(k q-l) .
$$

Then we have

$$
\alpha_{n}=\left(p b_{0}-b_{1}\right)(k q-l) q^{n-1}, \quad n \in \mathbb{N} .
$$

From (32) and (43), we have

$$
\left(p b_{0}-b_{1}\right)(k q-l) q \neq 0
$$

from which it follows that $\alpha_{n} \neq 0$ for every $n \in \mathbb{N}$. On the other hand, since $q<0$, we have that the subsequence $\left(\alpha_{2 n}\right)_{n \in \mathbb{N}}$ consists of negative (or positive) numbers only, whereas the subsequence $\left(\alpha_{2 n-1}\right)_{n \in \mathbb{N}}$ consists of positive (or negative) numbers only, which implies that it cannot be constant, and consequently (35) also cannot hold in this case.

Now assume

$$
\left(b_{1}-q b_{0}\right)(k p-l)=\left(p b_{0}-b_{1}\right)(k q-l)=0,
$$


then from (35) and since $p \neq q$, we would have $c=0$ and $b_{n}=0, n \in \mathbb{N}$, so consequently $x_{n}=2$ for every $n \in \mathbb{N}$, a case which is not much interesting.

Hence, (35) can hold only for a trivial solution in the case when (46) holds.

Case 2. Relation (29) holds. This case is essentially the same as the case when (28) holds, since it is obtained by replacing $c$ by $-c$. Hence, from the previous consideration, we see that

$$
\left(b_{1}-q b_{0}\right)(k p-l) p^{n-1}+\left(p b_{0}-b_{1}\right)(k q-l) q^{n-1}=c(q-p), \quad n \in \mathbb{N}
$$

also cannot hold, except for a trivial solution in the case when (46) holds.

Case 3. Relation (30) holds. By using formula (34) in (30), we obtain

$$
\left(b_{1}-q b_{0}\right)(k p-l) p^{n-1}+\left(p b_{0}-b_{1}\right)(k q-l) q^{n-1}=c(p-q)(-1)^{n}
$$

for $n \in \mathbb{N}$.

Assume that (37) holds. Then, by dividing both sides of relation (47) by $p^{n-1}$, we have that it must be

$$
\left(b_{1}-q b_{0}\right)(k p-l)+\left(p b_{0}-b_{1}\right)(k q-l)\left(\frac{q}{p}\right)^{n-1}=\frac{c(p-q)(-1)^{n}}{p^{n-1}}
$$

for $n \in \mathbb{N}$.

By letting $n \rightarrow+\infty$ in (48) and using (33), we get

$$
\left(b_{1}-q b_{0}\right)(k p-l)=0 \text {. }
$$

However, (49) contradicts one of the assumptions in (37), from which it follows that (47) cannot hold in this case.

Now assume that (40) holds. Then we have that it must be

$$
\left(b_{1}-q b_{0}\right)(k p-l) p^{n-1}=c(p-q)(-1)^{n}, \quad n \in \mathbb{N},
$$

which is only possible if

$$
p=-1 \quad \text { and } \quad\left(b_{1}-q b_{0}\right)(k p-l)=c(q-p) .
$$

But since $p>0$, the first equality in (50) is not possible, and consequently (47) also cannot hold in this case.

Now assume that (43) holds. Then, we have that it must be

$$
\left(p b_{0}-b_{1}\right)(k q-l) q^{n-1}=c(q-p)(-1)^{n-1}, \quad n \in \mathbb{N},
$$

which is only possible if

$$
q=-1 \quad \text { and } \quad\left(p b_{0}-b_{1}\right)(k q-l)=c(q-p)
$$

Bearing in mind (43), we see that there are two subcases to be considered. 
Subcase $q=-1, b_{0}=-b_{1}$. From (51) we have

$$
\left(p b_{0}-b_{1}\right)(k+l)(-1)^{n}=c(p-q)(-1)^{n},
$$

from which, along with the conditions $q=-1, b_{1}=-b_{0}$, it follows that

$$
b_{0}(k+l)=c .
$$

Since $q \neq p$ and $p=k+1=l$, we obtain

$$
c=b_{0}(2 k+1)=b_{0}(2 p-1) .
$$

Hence, in this case equation (24) becomes

$$
x_{n+1}=P_{k}\left(x_{n}\right) P_{k+1}\left(x_{n-1}\right)-a^{c}-a^{-c}
$$

for $n \in \mathbb{N}$, where $c$ is given by (53).

Since $b_{1}=-b_{0}$, it is easy to see that $x_{0}=x_{1}$. From (54) with $n=1$, since $b_{1}=-b_{0}$, and by using (53), we obtain

$$
\begin{aligned}
x_{2} & =P_{k}\left(x_{1}\right) P_{k+1}\left(x_{0}\right)-a^{c}-a^{-c} \\
& =\left(a^{k b_{1}}+a^{-k b_{1}}\right)\left(a^{(k+1) b_{0}}+a^{-(k+1) b_{0}}\right)-a^{c}-a^{-c} \\
& =\left(a^{k b_{0}}+a^{-k b_{0}}\right)\left(a^{(k+1) b_{0}}+a^{-(k+1) b_{0}}\right)-a^{c}-a^{-c} \\
& =a^{(2 k+1) b_{0}}+a^{-(2 k+1) b_{0}}+a^{b_{0}}+a^{-b_{0}}-a^{c}-a^{-c} \\
& =a^{b_{0}}+a^{-b_{0}} .
\end{aligned}
$$

From $x_{0}=x_{1}$ and (55), we have $x_{0}=x_{1}=x_{2}$. From this, by using (54) and the method of induction, it is proved that

$$
x_{n}=x_{0}=a^{b_{0}}+a^{-b_{0}}=a^{\frac{c}{2 k+1}}+a^{-\frac{c}{2 k+1}}, \quad n \in \mathbb{N},
$$

an equilibrium solution, which is not much interesting.

Subcase $q=-1, b_{1} \neq-b_{0}, k p=l$. Since $p=k+1$, from $k p=l$ and $l=p$, we get $k=1$ and $p=l=2$. From (51) we have

$$
\left((k+1) b_{0}-b_{1}\right)(k+l)(-1)^{n}=c(p-q)(-1)^{n},
$$

and consequently

$$
c=b_{0}(k+1)-b_{1}=2 b_{0}-b_{1} \text {. }
$$

Hence, in this case equation (24) becomes

$$
x_{n+1}=P_{1}\left(x_{n}\right) P_{2}\left(x_{n-1}\right)-a^{2 b_{0}-b_{1}}-a^{b_{1}-2 b_{0}},
$$


and its solution is given by

$$
x_{n}=a^{\frac{\left(b_{0}+b_{1}\right) 2^{n}-\left(b_{1}-2 b_{0}\right)(-1)^{n}}{3}}+a^{-\frac{\left(b_{0}+b_{1}\right) 2^{n}-\left(b_{1}-2 b_{0}\right)(-1)^{n}}{3}}
$$

for $n \in \mathbb{N}_{0}$.

Now assume that (46) holds. Then, from (35) and since $p \neq q$, we would have $c=0$ and $b_{n}=0, n \in \mathbb{N}$, so consequently $x_{n}=2$ for every $n \in \mathbb{N}$, a case which is not much interesting.

Case 4. Relation (31) holds. By using formula (34) in (31), we obtain

$$
\left(b_{1}-q b_{0}\right)(k p-l) p^{n-1}+\left(p b_{0}-b_{1}\right)(k q-l) q^{n-1}=c(p-q)(-1)^{n-1}, \quad n \in \mathbb{N},
$$

which is, in fact, (47) where $c$ is replaced by $-c$.

Hence, from the previous analysis, we see that (24) is solvable only if

$$
k=1, l=2, \quad \text { and } \quad c=-\left(2 b_{0}-b_{1}\right)=b_{1}-2 b_{0} .
$$

In this case equation (24) becomes (58), and its solution is given by (59).

From all the above mentioned we see that out of all the equations in (24), only the equations with $k=1, l=2$, and $c= \pm\left(2 b_{0}-b_{1}\right)$ are possible to solve by using the method from the second solution to Problem 1 . This, a bit surprising, result shows a very specific character of equation (7), or more concretely, the specificity of solvability of initial value problem (7)-(8). So, we have that the following extension of Proposition 1 holds.

Proposition 2 Let the sequence $\left(x_{n}\right)_{n \in \mathbb{N}_{0}}$ be the solution to the equation

$$
x_{n+1}=P_{1}\left(x_{n}\right) P_{2}\left(x_{n-1}\right)-a^{2 b_{0}-b_{1}}-a^{b_{1}-2 b_{0}}, \quad n \in \mathbb{N},
$$

satisfying the initial value conditions

$$
x_{0}=a^{b_{0}}+a^{-b_{0}} \text { and } x_{1}=a^{b_{1}}+a^{-b_{1}},
$$

where $a \in \mathbb{C} \backslash\{0\}$ and $b_{0}, b_{1} \in \mathbb{Z}$, or $a \in \mathbb{R} \backslash\{0\}$ and $b_{0}, b_{1} \in \mathbb{R}$. Then the sequence is given by closed-form formula (59).

Remark 1 Note that in the case when

$$
b_{0}=0 \text { and } b_{1}=1 \text {, }
$$

we have $c=-1$ (or $c=1$ ), so that equation (58) reduces to equation (7), and from formula (59) is obtained formula (20).

\section{Acknowledgements}

Not applicable.

Funding

Not applicable.

Availability of data and materials Not applicable. 


\section{Competing interests}

The author declares that he has no competing interests.

\section{Authors' contributions}

The author has contributed solely to the writing of this paper. He read and approved the manuscript.

\section{Publisher's Note}

Springer Nature remains neutral with regard to jurisdictional claims in published maps and institutional affiliations.

Received: 23 September 2020 Accepted: 20 January 2021 Published online: 30 January 2021

\section{References}

1. Ašić, M., et al.: Medjunarodne Matematičke Olimpijade, Društvo Matematičara. Fizičara i Astronoma SR Srbije, Beograd (1977) (in Serbian)

2. Bashmakov, M.I., Bekker, B.M., Gol'hovoi, V.M.: Zadachi po Matematike. Algebra and Analiz. Nauka, Moskva (1982) (in Russian)

3. Berezansky, L., Braverman, E.: On impulsive Beverton-Holt difference equations and their applications. J. Differ. Equ Appl. 10(9), 851-868 (2004)

4. Berg, L., Stević, S.: On some systems of difference equations. Appl. Math. Comput. 218, 1713-1718 (2011)

5. Bernoulli, D.: Observationes de seriebus quae formantur ex additione vel substractione quacunque terminorum se mutuo consequentium, ubi praesertim earundem insignis usus pro inveniendis radicum omnium aequationum algebraicarum ostenditur. Commentarii Acad. Petropol. III 1728, 85-100 (1732) (in Latin)

6. Boole, G.: A Treatsie on the Calculus of Finite Differences, 3rd edn. Macmillan, London (1880)

7. de Moivre, A.: Miscellanea Analytica de Seriebus et Quadraturis. J. Tonson \& J. Watts, Londini (1730) (in Latin)

8. de Moivre, A.: The Doctrine of Chances, 3rd edn. Strand Publishing, London (1756)

9. Euler, L:: Introductio in Analysin Infinitorum. Tomus Primus, Lausannae (1748) (in Latin)

10. Fort, T.: Finite Differences and Difference Equations in the Real Domain. Oxford Univ. Press, London (1948)

11. Jordan, C.: Calculus of Finite Differences. Chelsea, New York (1956)

12. Krechmar, V.A.: A Problem Book in Algebra. Mir Publishers, Moscow (1974)

13. Lagrange, J.-L.: OEuvres, t. II. Gauthier-Villars, Paris (1868) (in French)

14. Lagrange, J.-L.: Sur l'intégration d'une équation différentielle à différences finies, qui contient la théorie des suites récurrentes, Miscellanea Taurinensia. t. I, (1759), 33-42 (Lagrange OEuvres, I, 23-36, 1867) (in French)

15. Laplace, P.S.: Recherches sur l'intégration des équations différentielles aux différences finies et sur leur usage dans la théorie des hasards, Mémoires de l'Académie Royale des Sciences de Paris 1773, t. VII, (1776) (Laplace OEuvres, VIII, 69-197, 1891) (in French)

16. Markoff, A.A.: Differenzenrechnung. Teubner, Leipzig (1896) (in German)

17. Milne-Thomson, L.M.: The Calculus of Finite Differences. Macmillan, London (1933)

18. Mitrinović, D.S., Kečkić, J.D.: Metodi Izračunavanja Konačnih Zbirova/Methods for Calculating Finite Sums. Naučna Knjiga, Beograd (1984) (in Serbian)

19. Moiseeva, Z., Savin, A.: XVIII Olimpiada po matematike. Kvant 1976(12), 57-60 (1976) (in Russian)

20. Nörlund, N.E.: Vorlesungen Über Differenzenrechnung. Springer, Berlin (1924) (in German)

21. Papaschinopoulos, G., Schinas, C.J.: On the behavior of the solutions of a system of two nonlinear difference equations. Commun. Appl. Nonlinear Anal. 5(2), 47-59 (1998)

22. Papaschinopoulos, G., Schinas, C.J.: Invariants for systems of two nonlinear difference equations. Differ. Equ. Dyn. Syst. 7, 181-196 (1999)

23. Papaschinopoulos, G., Schinas, C.J.: Invariants and oscillation for systems of two nonlinear difference equations. Nonlinear Anal., Theory Methods Appl. 46, 967-978 (2001)

24. Papaschinopoulos, G., Stefanidou, G.: Asymptotic behavior of the solutions of a class of rational difference equations. Int. J. Difference Equ. 5(2), 233-249 (2010)

25. Schinas, C.: Invariants for difference equations and systems of difference equations of rational form. J. Math. Anal. Appl. 216, 164-179 (1997)

26. Schinas, C.: Invariants for some difference equations. J. Math. Anal. Appl. 212, 281-291 (1997)

27. Stević, S.: Sixteen practically solvable systems of difference equations. Adv. Differ. Equ. 2019, Article ID 467 (2019)

28. Stević, S.: Solvability of some classes of nonlinear first-order difference equations by invariants and generalized invariants. Electron. J. Qual. Theory Differ. Equ. 2019, Article ID 36 (2019)

29. Stević, S.: Solving a class of non-autonomous difference equations by generalized invariants. Math. Methods Appl. Sci. 42, 6315-6338 (2019)

30. Stević, S., Diblik, J., Iričanin, B., Šmarda, Z.: On a third-order system of difference equations with variable coefficients. Abstr. Appl. Anal. 2012, Article ID 508523 (2012)

31. Stević, S., Diblik, J., Iričanin, B., Šmarda, Z:: On some solvable difference equations and systems of difference equations Abstr. Appl. Anal. 2012, Article ID 541761 (2012)

32. Stević, S., Iričanin, B., Kosmala, W.: More on a hyperbolic-cotangent class of difference equations. Math. Methods Appl. Sci. 42, 2974-2992 (2019)

33. Stević, S., Iričanin, B., Kosmala, W., Šmarda, Z.: Note on the bilinear difference equation with a delay. Math. Methods Appl. Sci. 41, 9349-9360 (2018)

34. Stević, S., Iričanin, B., Kosmala, W., Šmarda, Z.: Representation of solutions of a solvable nonlinear difference equation of second order. Electron. J. Qual. Theory Differ. Equ. 2018, Article ID 95 (2018)

35. Stević, S., Iričanin, B., Kosmala, W., Šmarda, Z.: Solvability of a class of hyperbolic-cosine-type difference equations. Adv. Differ. Equ. 2020, Article ID 564 (2020)

36. Stević, S., Iričanin, B., Šmarda, Z.: On a symmetric bilinear system of difference equations. Appl. Math. Lett. 89, 15-21 (2019) 
37. Stević, S., Tollu, D.T.: Solvability and semi-cycle analysis of a class of nonlinear systems of difference equations. Math. Methods Appl. Sci. 42, 3579-3615 (2019)

38. Stević, S., Tollu, D.T.: Solvability of eight classes of nonlinear systems of difference equations. Math. Methods Appl. Sci. 42, 4065-4112 (2019)

39. Vorobiev, N.N.: Fibonacci Numbers. Birkhäuser, Basel (2002)

Submit your manuscript to a SpringerOpen ${ }^{\odot}$ journal and benefit from:

- Convenient online submission

$\checkmark$ Rigorous peer review

- Open access: articles freely available online

- High visibility within the field

- Retaining the copyright to your article

Submit your next manuscript at $\boldsymbol{~ s p r i n g e r o p e n . c o m ~}$ 